\title{
Fake News and Related Concepts: Definitions and Recent Research Development
}

\author{
Chih-Chien Wang \\ Graduate Institute of Information Management, National Taipei University, Taiwan \\ E-mail: wangson@mail.ntpu.edu.tw
}

\begin{abstract}
Fake news is an emerging field of research that attracts much attention from academic communities as well as mass media practitioners. However, the concept of fake news is still ambiguous, and the boundary between the definition of fake news and other relative concepts, such as news satire, yellow journalism, junk news, pseudonews, hoax news, propaganda news, advertorial, false information, fake information, misinformation, disinformation, mal-information, alternative fact, and post-truth is blurred. The present study aims to identify the meanings of fake news and other related concepts, and explore the recent trend of research on them. By searching the journals listed in the Social Sciences Citation Index (SSCI) and Science Citation Index Expanded (SCI-Expanded) database, the present study found 387 articles on fake news. Through analyzing these articles, the present study maps the trend and reveals the highly influential research articles, as well as theories and concepts that are used. The results may provide fundamental insights into the development of research on fake news in recent years.
\end{abstract}

Keywords: Fake news, False news, Disinformation, Misinformation, Bibliometric analysis

\section{INTRODUCTION}

The advancement and popularity of the Internet have enabled people to obtain and distribute news messages quickly and ubiquitously. People now use mobile phones and social media to obtain news messages. (Chiang, Wu, \& Yang, 2019). In the past, news reports were generated and distributed via conventional news media, such as newspapers, magazines, television, radio, and newsagents. However, in the Internet era, in addition to traditional news media, there are plenty of new media or channels 
delivering news, such as online news media, news aggregator websites, content websites, content farms, and social media. Since it is easy to create and spread news reports on the Internet, the news reports spread online are not necessarily from reputable news media.

The rapid distribution of news and messages on the Internet has changed the industry practice of the news industry (Westlund, 2013). Some of the news reports may contain fake or false facts purposely or unintentionally. For the purpose of attracting public attention, some news media and news reporters may exaggerate the news report statements, while some may even fabricate or distort the contents. Due to the fact that it is easy to register multiple accounts using fake demographic information on social media, some of these social media are full of fake accounts, which are used to deliver fake news to the public. Adding that spammers and fake news spreaders use social media to distribute fake news, it turns out that cyberspace is filled with fake or false messages.

Besides, many news media practitioners no longer examine the contents of the news reports seriously for better accuracy. Instead, an increasing number of news reporters are requested to provide news reports as quickly as they can in order to draw attention from the audience. With the requests of prompt responses to news events, reporters now rarely have sufficient time to check and confirm the information they have collected. Thus, some of the news reports may mistakenly contain incorrect facts. These incorrect news articles are spread over the cyberspace, making it full of fake or false messages.

Fake news, an issue coming along with the Internet, has existed for years, but relatively few people are aware of the presence of fake news. In the 2016 presidential election of the United States, there was enormous fake news (Persily, 2017). After 2016, fake news has gradually become a blooming topic of research. The impact of the spread of fake political news is one of the themes. A number of scholars focus their efforts on other aspects of fake news, such as the source of fake news, spreading behavior of fake news, the social impact of fake news, the persuasion effect of fake news, individuals' factors for fake news persuasion, and fake news detection.

Molina, Sundar, Le, and Lee (2019) revealed that fake news is not simply false information. How to characterize fake news has been a major concern for many researchers. News reports that contain incorrect news may not always be considered as fake news because people believe that the reporters do not purposely deliver the incorrect news. In contrast, people consider news reports with some facts to be fake because reporters put too many exaggerated statements in the news reports. This study aims to introduce the multiple facets of fake news and provide a comprehensive understanding of recent trends of fake news research. 
Most research on fake news argued that fake news is news with fake facts. However, there is still no consensus on the scope and the detailed definition of fake news, while there are some other terms carrying similar meanings to fake news. In this study, we aim to explore the research topics, scopes, and trends of research on fake news by using bibliometric and text mining techniques to analyze relevant academic articles published in recent years.

On the basis of academic articles published in Science Citation Index Expanded (SCI-Expanded) and Social Science Citation Index (SSCI), the present study makes use of bibliometric and text mining approaches to reveal the research directions of fake news, serving as a roadmap for both of the academic community and news media practitioners. The significance of this study is threefold: (1) Distinguish the meanings of similar terms to fake news; (2) Analyze the distribution of fake news, such as publication years, published journals, research fields, and citation times. (3) Discuss the topics and theoretical background of research on fake news by looking into the abstracts of the included articles.

This paper is structured into five sections. The first section provides a brief introduction of this study. Then, the second and third sections introduce the terms and concepts that are similar or relative to fake news and false information. In the fourth section, the authors report the bibliometric approach and explain the analysis results. Finally, the conclusion is presented with a discussion over research limitations and implications for future research.

\section{FAKE NEWS AND RELATED CONCEPTS}

Fake news, widely disseminated in cyberspace nowadays, is an emerging research field that attracts the attention of a group of scholars from different fields. Several terms are used interchangeably, for example, fake news, news satire, yellow journalism, junk news, pseudo-news, hoax news, propaganda news, advertorial, false information, fake information, misinformation, disinformation, mal-information, and alternative fact. The above-mentioned terms can be divided into two categories: terms with similar meaning to fake news and terms with similar meaning to false information. Essentially, fake news discusses the news that is put out by news media. False information discussed information that is distributed over the cyberspace. False information can be spread alone or included in fake news to be delivered. Thus, false information and its related terms have a larger range of scope compared with fake news. In this section, the paper firstly introduces fake news and its related terms. Then, the paper introduces false information and its related terms. 


\section{Fake News and Related Concepts}

Fake news does not always report non-existent news stories. It rarely happens that the whole news story is fabricated, although pure fabrication is still a possible source of false information.

In general, fake news refers to news messages that contain wrong or false information but do not report the incorrectness of information. However, not all papers adopt this definition of fake news. Some researchers, such as Allcott and Gentzkow (2017) defined fake news as news that is intentionally written to mislead the readers but can be verified to be false. This kind of definition in turn raises the issue that who has the authority and the ability to decide if the news is intentionally written to mislead the audience. If a news report claims that the news does not purposely include the incorrect facts, should the news with the incorrect fact be deemed fake news or not? The core concept is that fake news is news with incorrect facts, whereas motivation is an accompanying issue when discussing fake news. Not all incorrect facts are spread purposely; some are distributed unintentionally, though. Researchers have to decide by themselves if they consider the news that mistakenly includes incorrect facts as fake news.

There exist multiple meanings of fake news that need to be clarified. On the other hand, there are some terms with similar meanings to fake news. Junk news, pseudonews, alternative fact, hoax news are terms with similar meaning to fake news. In this case, fake news refers to inaccurate facts distributed in cyberspace in the sense that the inaccurate facts are spread online rather than in the format of news reports. These inaccurate or incorrect messages are named as disinformation, misinformation, malinformation, and rumors that are related to fake news.

News satire, yellow journalism, junk news, pseudo-news, hoax news, propaganda news, advertorial are terms with similar meaning to fake news. Some people may consider these terms as synonyms for fake news. For example, some people may consider news satire as fake news since news satire is not real news. Some may believe yellow journalism is a type of fake news because it is the use of sensational headlines, rather than factual news, to capture a reader's attention. Some may consider fake news as junk news since fake news is also meaningless like trash but disseminated in bulk. Some may consider fake news as pseudo-news that reports a non-existent story. Nevertheless, there are still some differences among these terms.

The paper provides simplified definitions of the term "fake news" and related concepts (shown in Table 1) and discusses these terms as below. Rather than setting the boundary between each term, the present study focuses more on claiming that different studies may have different ranges of research scope of fake news. Recognizing the 
multiple facets of fake news is crucial to comprehend the content of previous research on fake news.

\section{Fake News}

Fake news refers to news messages that contain incorrect or false information but do not report the incorrectness of information. It is the core concept in the research of fake news. However, not all studies adopt this definition of the term "fake news". Tandoc Jr, Lim, and Ling (2018) revealed that in the literature, there are different definitions based on two dimensions: levels of facticity and deception.

\section{False News}

It is not easy to distinguish fake news from false news. All too often, the terms fake news and false news can be used interchangeably. However, fake news is news that is deliberately fabricated, while false news is with inaccurate information, whether it is created intentionally or mistakenly. It is observed that Facebook has stopped saying fake news and replaced it with the term "false news"1. Nevertheless, there is still no consensus on the difference between "fake news" and "false news" for most scholars.

\section{News Satire}

News satire is a type of humorous TV show or a satirical article that the audience knows the content of the news satire is not always correct. Some media companies constantly publish news satire, such as the Onion ${ }^{2}$, a U.S. based satirical newspaper organization.

Although news satire does not report real facts, it is different from fake news. The purpose of news satire is to have fun and to cheer the audience. However, in some cases, people might mistakenly treat news satire as actual news. Audiences with no knowledge about the satirical media may consider satirical news reported by the satirical media as real news.

\section{Yellow Journalism}

Yellow journalism uses shocking headlines, exaggerating facts, or rumors to catch audience attention. Yellow journalism might help with the spread of fake news. In some forms of yellow journalism, the news content is real but with shocking headlines. Thus, yellow journalism is not always identical to fake news since some yellow journalism just uses shocking headlines that catch audience attention. Nevertheless, yellow

\footnotetext{
${ }^{1}$ https://slate.com/technology/2017/08/facebook-has-stopped-saying-fake-news-is-false-news-anybetter.html

${ }^{2}$ https://en.wikipedia.org/wiki/The_Onion
} 
journalism is indeed an important source of fake news, since it may exaggerate the facts or promote the spread of rumors.

\section{Junk News}

The concept of junk news emphasizes the news is massively disseminated with the content of propaganda and ideologically extreme, hyper-partisan, or conspiratorial political information. The term "junk" is used to reflect the news is considered as junk since the contents are as useless as trash.

Junk news discusses the topic that the audience does not care about. Not all fake news can be characterized as junk news because some fake news is treated as an important message rather than a junk message by some targeted audience.

\section{Pseudo-News}

Pseudo-news reports a non-existent story. The whole story does not exist. Fake news is also not identical to pseudo-news in the sense that some fake news actually exists but with some misleading or false details. It is called fake news because the news contains incorrect content, whereas pseudo-news indicates that the news story does not exist.

\section{Hoax News}

Hoax is defined as a humorous or malicious deception. Hoax news refers to news that contains humorous or malicious deceptions. The incorrect messages are purposely, not mistakenly included in hoax news. However, in some cases, hoax news is deemed a joke, such as April Fools' Day hoax.

\section{Propaganda News}

Propaganda news is a paid news report containing propaganda messages that disguise as news. However, propaganda news usually reports a real but prettified fact. News media receive sponsorship to deliver the propaganda news. The audience cannot be sure that the news is not a normal news report since it does not disclose the source, the funding provider, and the motivation.

Propaganda news is not fake news since it does not include wrong or false information. Propaganda news is not a normal news report since it is purposely provided to deliver some specific information. Propaganda news is a paid message but not a commercial message since it looks like a news report rather than an advertisement or advertorial.

\section{Advertorial}


Advertorial, a compound term combining "advertising" and "editorial", is referred to as a news report that contains commercial messages. The advertorial is an advertisement that looks like a news story and usually contains a sponsor message for the purpose of marketing communication. However, it usually presents itself as an advertorial or a commercial. The content of an advertorial is a commercial rather than a news story. An advertorial is not fake news since it is not news and does not include any wrong or false information. Some people may think that an advertorial is a type of fake news because it deceives the readers by advertising that uses news reporting formats to present commercial information. In other words, the content of an advertorial is not news, but it looks like a news report. However, an advertorial usually presents itself as a commercial message and discloses its source, the funding provider, and the motivation.

The advertorial looks like a news story. However, it usually presents itself as an advertorial or a commercial. An advertorial is a commercial rather than a news story. An advertorial is not fake news since it is not news and does not include any wrong or false information. 
Table 1 Definitions of Fake News and Related Terms

\begin{tabular}{|c|c|}
\hline Term & Definition \\
\hline Fake news & $\begin{array}{l}\text { Fake news refers to a message that contains wrong or false } \\
\text { information but does not report the incorrectness of } \\
\text { information. }\end{array}$ \\
\hline News satire & $\begin{array}{l}\text { News Satire is a type of parody, usually with ironic humor, } \\
\text { presented in the form of an ordinary news report. }\end{array}$ \\
\hline Yellow journalism & $\begin{array}{l}\text { Yellow journalism uses shocking or clickbait headlines, } \\
\text { exaggerating facts, or rumors to catch audience attention. }\end{array}$ \\
\hline Junk news & $\begin{array}{l}\text { Junk news refers to the news content that is considered as } \\
\text { useless as trash. The concept of junk news emphasizes that } \\
\text { the news includes propaganda and ideologically extreme, } \\
\text { hyperpartisan, or conspiratorial political news and } \\
\text { information, and are massively disseminated. }\end{array}$ \\
\hline Pseudo-news & $\begin{array}{l}\text { Pseudo-news refers to news that reports a non-existent story. } \\
\text { The whole story does not exist. }\end{array}$ \\
\hline Hoax news & $\begin{array}{l}\text { Hoax news refers to news that contains humorous or } \\
\text { malicious deceptions. }\end{array}$ \\
\hline Propaganda news & $\begin{array}{l}\text { Propaganda news is a paid news report containing } \\
\text { propaganda messages that disguise as a news report but does } \\
\text { not disclose the source, the funding provider, and the } \\
\text { motivation. }\end{array}$ \\
\hline Advertorial & $\begin{array}{l}\text { The advertorial is an advertisement that is presented in the } \\
\text { format of a news report. }\end{array}$ \\
\hline Advertisement & $\begin{array}{l}\text { The concept of advertisement is different from fake news } \\
\text { since the audience can easily recognize that the messages are } \\
\text { provided by companies or organizations. }\end{array}$ \\
\hline
\end{tabular}

\section{FALSE INFORMATION AND RELATED CONCEPTS}

Fake news and its related concepts share a common element: incorrect information. When discussing incorrect information in fake news, people usually bring up other terms with similar but different meanings, such as false information, misinformation, 
disinformation, mal-information, and alternative fact. Although all these terms are used to describe incorrect information, there are not identical. However, the boundary between each of these terms is ambiguous, and people tend to get confused when trying to distinguish them from one another. We try to explain the difference between each of these terms. Nevertheless, these terms are used interchangeably in some cases.

The paper provides a simplified definition of the term "false news" and related concepts (shown as Table 2) and discusses these terms as below. This study suggests that different studies may have different ranges of the scope of research on false information. Recognizing the multiple facets of false information is important to understand the content of previous literature about fake news and false information.

\section{False Information}

False information refers to incorrect information. However, the term "false information" does not involve any motivation. It just reveals the fact that the information is not correct.

\section{Fake Information}

Fake news is frequently used. Thus, the term fake information is naturally used. Nevertheless, the terms "fake information" is not so frequently used as false information.

\section{Misinformation}

The meaning of misinformation is similar to that of false information. However, according to the definition of the dictionary by Merriam-Webster, misinformation refers to "incorrect or misleading information ${ }^{3}$ ". In some cases, misinformation is not incorrect but misleading. The misinformation maybe not incorrect, but the statement of the misinformation may mislead the audience.

\section{Disinformation}

Disinformation refers to the deliberate and covert spread of false information to influence public opinion. Unlike misinformation, which does not reveal the purpose of incorrect information, disinformation is deliberately created to harm others. According to the definition by United Nations Educational, Scientific and Cultural Organization (UNESCO), disinformation is "Information that is false and deliberately created to harm a person, social group, organization or country ${ }^{4}$ ".

\footnotetext{
3 https://www.merriam-webster.com/dictionary/misinformation

${ }^{4}$ https://en.unesco.org/fightfakenews
} 


\section{Mal-Information}

Mal-information refers to information used to hurt others. Mal-information is also a term that is easy to be confused with disinformation. However, unlike disinformation, which is incorrect information, mal-information refers to "information that is based on reality, used to inflict harm on a person, social group, organization or country 5 ". Malinformation is based on reality. Thus, it is another research focus area.

\section{Alternative Fact}

An alternative fact does not mean a fact. It is a mis-statement of fact. It is not easy to understand since the term contains the word "fact" but does not mean a fact. Alternative facts appeared after the false statement about the number of attendees in the United States presidential inauguration on January 20, 2017. Fake news is not always an alternative fact since, in some cases, fake news is not based on any truth. Nevertheless, an alternative fact is based on the truth but a misstatement of the truth.

\section{Post-Truth}

Post-truth does not mean the truth. It is not easy to understand since the term contains the word "truth" but does not mean truth. Post-truth refers to a political concept that with the disappearance of shared objective standards for truth, the message is regarded as truth, but the message itself is considered false according to scientific inquiries

\footnotetext{
5 https://en.unesco.org/fightfakenews
} 
Table 2 Definitions of False Information and Relative Terms

\begin{tabular}{|c|l|}
\hline Terms & \multicolumn{1}{|c|}{ Definition } \\
\hline False Information & False information refers to incorrect information. \\
\hline Fake Information & Fake information refers to incorrect information. \\
\hline Misinformation & Misinformation refers to incorrect and misleading information. \\
\hline Disinformation & $\begin{array}{l}\text { Disinformation refers to deliberately and covertly spread false } \\
\text { information to influence public opinion. }\end{array}$ \\
\hline Mal-information & Mal-information refers to information used to hurt others. \\
\hline Alternative fact & An alternative fact refers to a misstatement of the fact. \\
\hline Post-truth & $\begin{array}{l}\text { Post-truth refers to consider a statement as truth because of a } \\
\text { political standpoint. Post-truth refers to a political concept of the } \\
\text { disappearance of shared objective standards for truth. Post-truth } \\
\text { considers a message as truth, but the message itself is considered } \\
\text { as false by scientific inquiries. }\end{array}$ \\
\hline
\end{tabular}

As mentioned above, researchers may define fake news as news that is intentionally written to mislead the audiences. Thus, the purpose of incorrectness is the key idea for some research on fake news. Table 3 shows the truthiness and purposes of incorrect information. The term "disinformation" is frequently used to describe the incorrect information that is deliberately spread. The term "mal-information" is frequently used to describe the information that is deliberately spread to inflict harm on others. 
Table 3 Truthiness and Purpose of False information and relative terms

\begin{tabular}{|c|c|c|}
\hline Term & Truthiness & Purpose \\
\hline False information & Incorrect & N/A \\
\hline Fake information & Incorrect & N/A \\
\hline Misinformation & Incorrect or misleading & Not purposely created to harm others \\
\hline Disinformation & Incorrect & Deliberately created to harm others \\
\hline Mal-information & Correct or Incorrect & Inflict harm on others \\
\hline Alternative fact & Incorrect & Misstatement of the truth \\
\hline
\end{tabular}

\section{BIBLIOMETRIC ANALYSIS}

\section{Database Search}

This study aims to provide a comprehensive understanding of the recent trend of research on fake news. However, there are plenty of academic journals published all over the world. In order to limit the search results to allow scholars to focus on more influential articles, this study limited the search scope to journals indexed in Social Science Citation Index (SSCI) and Science Citation Index Expanded (SCI-Expanded), and used the fore-mentioned terms to search for papers included in SSCI/SCIExpanded. In addition, the paper limited the search scope to "articles" only and did not include the reviews, conference proceedings, corrections, editorial materials, letters, book reviews, book chapters, news reports, and meeting abstracts. The paper also limited the language to English and did not include articles published in other languages. In order to reveal the recent trend of paper publication, this study limited the range of publication year to the years 2019 and before.

The current study conducted two searches: paper title search and paper topic search. Paper title search limits the search scope to the title of papers, while paper topic search expands the scope to title, abstract, and keywords of papers. If an article is with a title containing the above-mentioned terms, its main content is highly possibly close to them. If the search term only appears in the abstract or keyword list, that paper may only be related to the search terms but not focus mainly on that term. In some cases, papers might just mention the search terms as part of background information rather than focusing on the search terms. The present paper records the numbers of search terms that appear in titles and topics of papers included in SSCI/SCI-Expanded.

In this study, we used the exact comparison approach (search papers for the exact phrases) for the search terms. For example, a paper with the title "fake sources of news 
media" would be excluded since it was not using the exact phrase "fake news". Exact comparison has the disadvantage that some papers may be missed. For example, "fake science news" was not considered as "fake news" inexact comparison.

\section{Fake News and Related Terms}

As mentioned above, there are similar terms that relate to fake news and false information, and we first check the use of these terms in previous literature. As table 4 indicates, the term fake news was frequently used in the literature: 170 papers had included fake news in their titles, and 370 papers had mentioned fake news in their titles, abstracts, or keyword lists. Some papers had used the term false news ( 9 papers included the term in their titles, and 28 papers included the term in their titles, abstracts, and keyword lists). The term advertorial ( 5 papers in their titles, and 20 papers in paper titles, abstracts, and keyword lists) and news satire (3 papers in their titles, and 17 papers in paper titles, abstracts, and keyword lists) were also used. The other terms, such as yellow journalism, junk news, pseudo-news, hoax news, and propaganda news, were less used.

Table 4 Literature Search Results for Fake News and Relative Terms

\begin{tabular}{|c|c|c|}
\hline Terms & $\begin{array}{c}\text { Topic Search } \\
\text { (appear in title, abstract, } \\
\text { or keywords) }\end{array}$ & $\begin{array}{c}\text { Title Search } \\
\text { (appear in paper title) }\end{array}$ \\
\hline Fake news & 370 & 170 \\
\hline False news & 28 & 9 \\
\hline News satire & 17 & 3 \\
\hline Yellow journalism & 6 & 3 \\
\hline Junk news & 5 & 2 \\
\hline Pseudo-news & 0 & 0 \\
\hline Hoax news & 1 & 0 \\
\hline Propaganda news & 1 & 0 \\
\hline Advertorial & 20 & 5 \\
\hline Total & 417 & 190 \\
\hline
\end{tabular}

Note. Since one paper can discuss more than one concept, the total number is not equal to the summary of the number of all terms. 
As table 5 shows, the term rumor was frequently used in the literature: 737 papers had included rumor in their titles, and 4,059 papers had used rumor in paper titles, abstracts, or keyword lists. Nevertheless, the rumor is a traditional research topic which is not identical to fake news. In addition to rumor, misinformation was frequently used in the literature: 447 papers had included misinformation in their titles, and 2,394 papers had used misinformation in paper titles, abstracts, or keyword lists. Some papers had used the term disinformation (71 papers included the term in their titles, and 246 papers included the term in paper titles, abstracts, and keyword lists). The term false information (31 papers in paper titles, and 359 papers in paper titles, abstracts, and keyword lists) and fake information (1 paper in the paper title, and 27 papers in paper titles, abstracts, and keyword lists) were also often seen. The other terms, such as malinformation and alternative fact, were less used.

Table 5 Literature Search Results for Fake News and Relative Terms

\begin{tabular}{|c|c|c|}
\hline Terms & $\begin{array}{c}\text { Title, Abstract, Keywords } \\
\text { Search }\end{array}$ & Title Search \\
\hline Fake information & 27 & 1 \\
\hline False information & 359 & 31 \\
\hline Misinformation & 2394 & 447 \\
\hline Disinformation & 246 & 71 \\
\hline Rumor & 4059 & 737 \\
\hline Mal-information & 4 & 0 \\
\hline Post-Truth & 207 & 107 \\
\hline Alternative fact & 1 & 1 \\
\hline Total & 6,894 & 1,273 \\
\hline
\end{tabular}

Note. Since one paper can discuss more than one concept, the total number is not equal to the summary of the number of all terms.

As table 4 and table 5 show, theses terms news satire, yellow journalism, junk news, pseudo-news, hoax news, propaganda news, fake information, mal-information, and alternative fact were not frequently used in SSCI/SCI-expanded papers. In addition, 
the meanings of the terms advertorial and rumor were significantly different from those of fake news and false information. Thus, this study focuses effort on the terms of fake news, false news, false information, misinformation and disinformation, and excludes academic articles that only mentioned the terms news satire, yellow journalism, junk news, pseudo-news, hoax news, propaganda news, fake information, mal-information, alternative fact, rumor, and advertorial.

The paper searches papers with the terms of fake news, false news, false information, misinformation, and disinformation in the paper titles (Table 6) and in paper titles, abstracts, or keyword lists (Table 7). As table 6 and table 7 show, the number of papers with the title of fake news dramatically increased in 2017, while it was rarely used before 2017 in academic papers. Only a limited number of papers had mentioned the term false news in paper titles, abstracts, and keyword lists. In 2019, there were 223 papers with the term fake news in their paper titles, abstracts, and keywords. However, only 9 papers were with paper titles containing the term of false news in 2019. We can conclude that the term false news was rarely used. 
Table 6 Topic Search Results by Years

\begin{tabular}{|c|c|c|c|c|c|}
\hline Year & fake news & false news & $\begin{array}{l}\text { false } \\
\text { information }\end{array}$ & $\begin{array}{l}\text { misinformatio } \\
\mathrm{n}\end{array}$ & disinformation \\
\hline 2019 & 223 & 9 & 55 & 345 & 90 \\
\hline 2018 & 105 & 9 & 50 & 229 & 39 \\
\hline 2017 & 31 & 4 & 27 & 197 & 14 \\
\hline 2016 & 2 & 1 & 22 & 156 & 12 \\
\hline 2015 & 1 & 0 & 25 & 161 & 6 \\
\hline 2014 & 1 & 1 & 21 & 126 & 8 \\
\hline 2013 & 4 & 0 & 18 & 131 & 4 \\
\hline 2012 & 0 & 0 & 14 & 118 & 4 \\
\hline 2011 & 0 & 2 & 10 & 73 & 3 \\
\hline 2010 & 1 & 1 & 13 & 84 & 4 \\
\hline 2009 & 0 & 0 & 11 & 76 & 4 \\
\hline 2008 & 1 & 0 & 5 & 60 & 6 \\
\hline 2007 & 0 & 0 & 10 & 60 & 3 \\
\hline 2006 & 0 & 0 & 10 & 55 & 8 \\
\hline 2005 & 1 & 0 & 6 & 46 & 2 \\
\hline 2004 & 0 & 0 & 4 & 60 & 3 \\
\hline 2003 & 0 & 0 & 2 & 36 & 5 \\
\hline 2002 & 0 & 0 & 3 & 41 & 1 \\
\hline 2001 & 0 & 0 & 3 & 35 & 2 \\
\hline 2000 & 0 & 1 & 5 & 29 & 1 \\
\hline $2000-2019$ & 370 & 28 & 314 & 2118 & 219 \\
\hline $\begin{array}{c}1999 \text { and } \\
\text { before }\end{array}$ & 0 & 0 & 45 & 276 & 27 \\
\hline
\end{tabular}

Note. Topic search means that the searched terms appeared in the paper title, abstract, and keyword. 
Table 7 Title Search Results by Years

\begin{tabular}{cccccc}
\hline Year & fake news & false news & $\begin{array}{c}\text { false } \\
\text { information }\end{array}$ & $\begin{array}{c}\text { misinformati } \\
\text { on }\end{array}$ & $\begin{array}{c}\text { disinformatio } \\
\text { n }\end{array}$ \\
\hline 2019 & 105 & 4 & 7 & 68 & 22 \\
2018 & 46 & 3 & 4 & 35 & 7 \\
2017 & 15 & 0 & 1 & 40 & 2 \\
2016 & 2 & 0 & 1 & 24 & 3 \\
2015 & 0 & 0 & 2 & 31 & 3 \\
2014 & 0 & 0 & 2 & 19 & 3 \\
2013 & 2 & 0 & 0 & 26 & 3 \\
2012 & 0 & 0 & 0 & 19 & 2 \\
2011 & 0 & 1 & 1 & 11 & 2 \\
2010 & 0 & 1 & 0 & 16 & 0 \\
2009 & 0 & 0 & 0 & 6 & 2 \\
2008 & 0 & 0 & 1 & 6 & 0 \\
2007 & 0 & 0 & 0 & 13 & 0 \\
2006 & 0 & 0 & 0 & 8 & 0 \\
2005 & 0 & 0 & 0 & 6 & 0 \\
2004 & 0 & 0 & 1 & 7 & 1 \\
2003 & 0 & 0 & 0 & 7 & 1 \\
2002 & 0 & 0 & 1 & 9 & 0 \\
2001 & 0 & 0 & 0 & 6 & 0 \\
2000 & 0 & 0 & 1 & 7 & 0 \\
\hline $2000-2019$ & 170 & 9 & 22 & 364 & 51 \\
\hline 1999 and & 0 & 0 & 9 & 83 & 20 \\
before & 0 & & & & \\
\hline & & 0 & 0 & 0 & \\
\hline
\end{tabular}

Note. Title search means that the searched terms appeared in the paper title.

The term misinformation has also been frequently used in the past twenty years (2000-2019), and the number was increasing recently. However, when checking the research fields in which papers containing the term misinformation in the titles, abstracts, and keyword lists, we found $33.79 \%$ in psychology and $9.06 \%$ in public environmental occupational health. Thus, most of the misinformation papers had nothing to do with fake news.

The term disinformation was used recently with the increasing number of papers using disinformation in their titles, abstracts, and keyword lists, yet still less used, compared with misinformation. Although it is said that fake news is news with false 
information, only a limited number of papers have contained false information in their paper titles, abstracts, and keyword lists.

Most papers used the terms of fake news and misinformation. There has been an increasing number of fake news research articles since 2016. Among the 390 papers published during the period of 2000 to 2019 that contained fake news in paper titles, abstracts, and keyword lists, 379 (97.2\%) were published in 2017, 2018, and 2019. Among the 170 papers with fake news in the paper titles published during the period 2000 to 2019, 166 (97.6\%) were published in 2017, 2018, and 2019. Thus, it can be concluded that fake news is a new term frequently used after 2017.

While most papers used the term fake news, some still chose to use the term false news. There are 28 papers containing false news in their titles, abstracts, and keyword lists during the period 2000 to 2019. Among them, however, 22 (78.6\%) were published in 2017,2018 , and 2019. Among 9 papers with the term false news in their paper titles published during the period 2000 to 2019,7 (77.8\%) published was in 2017, 2018, and 2019.

Obviously, the rising of research on fake news is associated with the 2016 United States Presidential Election. During that election, people were aware of the influence of fake news, and Academic communities started to move their attention to this issue after the 2016 election.

The current study focuses on fake news research though. Some previous literature used the term "false news". Thus, the current study searched papers for the terms "fake news" and "false news" in the paper titles, abstracts, and keyword lists. Papers that discussed misinformation or disinformation rather than fake news or false news were not included in the present study. Papers that discussed misinformation or disinformation but contained fake news or false news in the abstracts were included in the current study. Table 8 reveals the database search terms. A total of 387 papers that contained the terms "fake news" or "false news" were found and included in this study.

Table 8 Database Search Terms

\begin{tabular}{|c|l|}
\hline & \multicolumn{1}{c|}{ Database Search Terms } \\
\hline Fake News Research & $\begin{array}{l}\text { The terms of "fake news" or "false news" appeared in the } \\
\text { paper title, abstract, or keywords. }\end{array}$ \\
\hline
\end{tabular}

This study aims to explore the recent development of fake news research by identifying 387 research articles published in SSCI/SCI-expanded indexed journals. Without exhaustive articles included though, the current study hopes to serve as a 
comprehensive basis for understanding the recent trend of research on fake news. This study collected the bibliographic data of these 387 fake news related articles to see the distribution of publication years, countries of authors, and journals that published these articles.

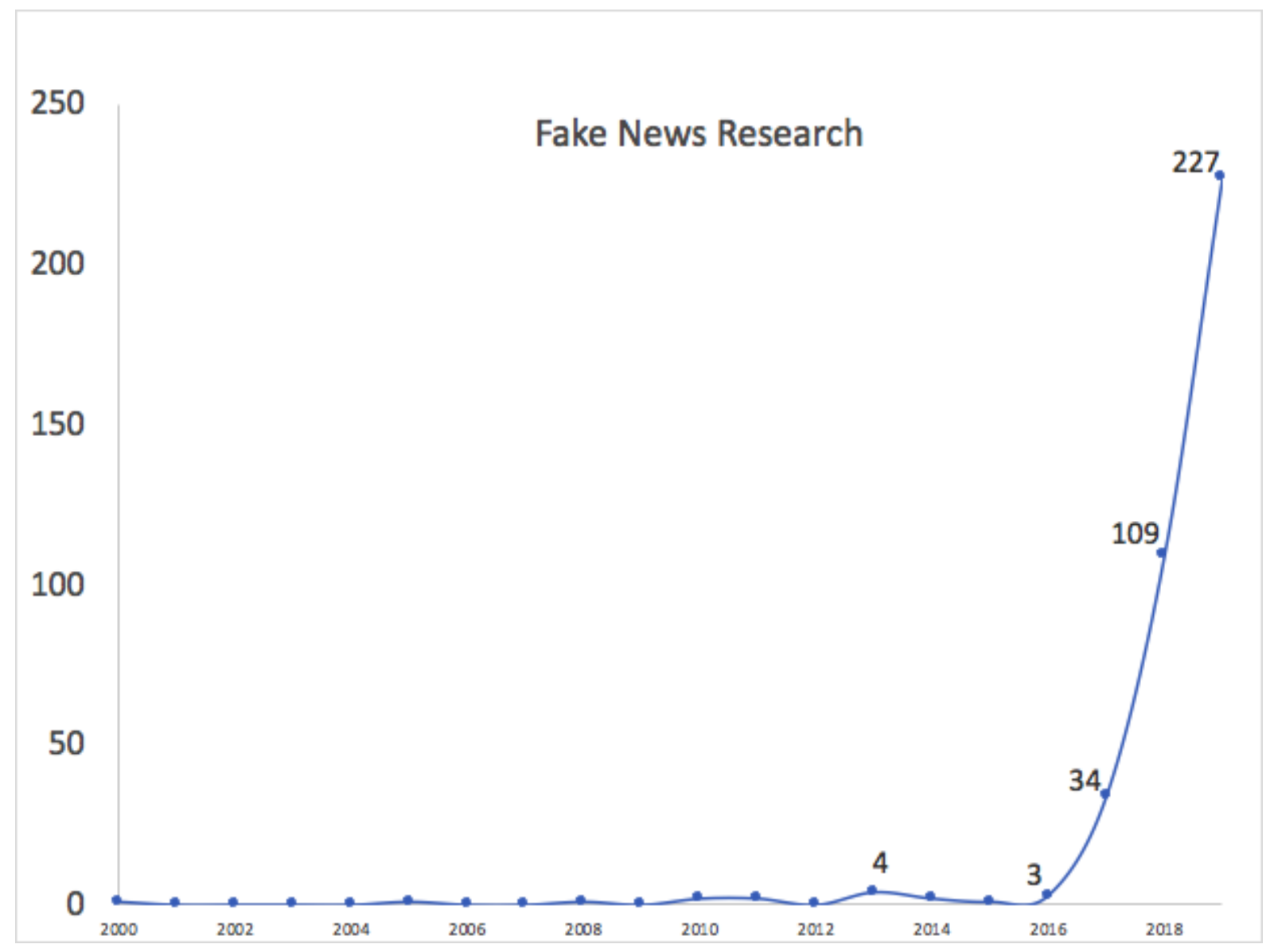

Figure 1 Distribution of Publication Years

\section{Distribution of the Year of Publication}

Figure 1 illustrates the number of published fake news research studies from 2000 to 2019, respectively. As Figure 1 reveals, only a few fake research articles were published before 2016. Nevertheless, the number of published fake news articles dramatically increased from 3 in 2016 to 34 articles in 2017, 109 in 2018, and 227 in 2019. The increase in the number of fake news articles demonstrates that academic communities and researchers have gradually paid attention to fake news.

\section{Distribution of Fake News Research Articles by Journals}

Table 9 reveals the distribution of fake news research articles by journals. There is no dominant journal in terms of the number of fake news articles published. Both Digital Journalism and International Journal of Communication, the top two journals in 
quantity, published 12 articles (3.1\% of the published fake news articles). They were followed by American Behavioral Scientist, Journalism Practice, and Social Media and Society, each of them published eight papers (2.1\% of the published fake news articles). Journals that published more than six papers on fake news included Culture and Education, Journalism Studies, New Media \& Society, Computers in Human Behavior, Online Information Review, and PLOS One.

\section{Distribution by Authors' Countries}

Table 10 reveals the distribution of authors' countries of these 387 fake news research studies. Through the authors' affiliations, this study identified the countries producing most fake news related articles. The five most prolific authors in fake news articles were the USA (45.7\%), England (10.9\%), Australia (8.0\%), Canada (7.8\%), and China $(5.7 \%)$. As table 10 shows, the United States scholars contributed most fake news articles and were interested in fake news research.

Table 9 Fake News Publications by Journals

\begin{tabular}{lcc}
\hline \multicolumn{1}{c}{ Journal } & Articles & Percentage \\
\hline Digital Journalism & 12 & $3.1 \%$ \\
International Journal of Communication & 12 & $3.1 \%$ \\
American Behavioral Scientist & 8 & $2.1 \%$ \\
Journalism Practice & 8 & $2.1 \%$ \\
Social Media Society & 8 & $2.1 \%$ \\
Culture and Education & 7 & $1.8 \%$ \\
Journalism Studies & 7 & $1.8 \%$ \\
New Media Society & 7 & $1.8 \%$ \\
Computers in Human Behavior & 6 & $1.6 \%$ \\
Online Information Review & 6 & $1.6 \%$ \\
PLOS One & 6 & $1.6 \%$ \\
\hline
\end{tabular}

Note. Only journals that included six or more fake news articles are included. 
Table 10 Fake News Publications by Authors' Countries

\begin{tabular}{|c|c|c|}
\hline Country & Articles & Percentage \\
\hline USA & 177 & $45.7 \%$ \\
\hline England & 42 & $10.9 \%$ \\
\hline Australia & 31 & $8.0 \%$ \\
\hline Canada & 30 & $7.8 \%$ \\
\hline China & 22 & $5.7 \%$ \\
\hline Italy & 17 & $4.4 \%$ \\
\hline Germany & 15 & $3.9 \%$ \\
\hline South Korea & 15 & $3.9 \%$ \\
\hline Spain & 14 & $3.6 \%$ \\
\hline Netherlands & 11 & $2.8 \%$ \\
\hline Singapore & 10 & $2.6 \%$ \\
\hline Brazil & 9 & $2.3 \%$ \\
\hline Norway & 9 & $2.3 \%$ \\
\hline Sweden & 9 & $2.3 \%$ \\
\hline India & 8 & $2.1 \%$ \\
\hline Switzerland & 6 & $1.6 \%$ \\
\hline Belgium & 5 & $1.3 \%$ \\
\hline Denmark & 5 & $1.3 \%$ \\
\hline Finland & 5 & $1.3 \%$ \\
\hline Scotland & 5 & $1.3 \%$ \\
\hline France & 4 & $1.0 \%$ \\
\hline Portugal & 4 & $1.0 \%$ \\
\hline South africa & 4 & $1.0 \%$ \\
\hline Taiwan & 4 & $1.0 \%$ \\
\hline
\end{tabular}

Note. Only countries that published more than $1.0 \%$ of fake news articles are included in this table. 


\section{Highly Influential Fake News Research Articles}

Table 11 reveals the highly impactful fake news articles. Although fake news is a new issue, some papers have received a lot of citations. For example, Vosoughi, Roy, and Aral (2018) had received more than 556 citations from other SSCI/SCI-expanded indexed papers, while the paper by Tandoc Jr et al. (2018) also received at least 195 citations. Both these two papers were published in 2018 and earned a lot of citations within a short period. There are 13 papers that have received more than 50 citations, as Table 11 illustrates. 12 of these 13 papers were published after 2016. These papers received many citations during a short period, showing that these fake news research studies earned a lot of attention after publication.

\section{Keywords Used in Fake News Research Articles}

Keywords represent the most important concepts that the authors believe they can best describe the core contents of their papers. Almost all academic journals provide several keywords for the published articles. Readers can use the keywords to realize the core themes that are highly relevant to the research articles.

In order to understand the main focus of the recently published fake news research articles, the current paper used term frequency to summarize all the keywords of the 387 fake news research articles. The current study adopts the term frequency (TF), which is a frequently used text mining technique to report how often a term occurs in a document. Previous literature had used it to summarize key concepts in documents (Noh, Jo, \& Lee, 2015; Yang \& Hwang, 2020).

Table 12 reveals the keywords used in the fake news articles. These keywords can be divided into five categories (shown in table 13): Fake news and related concepts, social media, social issues, fact-checking using artificial intelligence analysis, and others. The most frequently used keywords in the category of fake news and related concepts include fake news, misinformation, disinformation, propaganda, post-truth, false news, and alternative facts. The most frequently used keywords in social media include social media, social networks, twitter, and Facebook. Twitter and Facebook are social media that are frequently discussed. The most frequently used keywords include social issues, politics, elections, journalism, media, news, political communication, polarization, credibility, and narrative. The most frequently used keywords include machine learning, fact-checking, text mining, verification. These articles used text mining and artificial intelligence techniques to analyze and detect fake news. In addition to the above-mentioned keywords, there are some other keywords, such as populism, science, trump, media literacy, digital literacy, and trust. 
Table 11 Highly Influence Fake News Research Articles

\begin{tabular}{|c|c|c|c|c|}
\hline Authors & Paper Title & Journal & $\begin{array}{l}\text { Citation } \\
\text { Times }\end{array}$ & $\begin{array}{l}\text { Publish } \\
\text { Year }\end{array}$ \\
\hline $\begin{array}{l}\text { Vosoughi et al. } \\
\text { (2018) }\end{array}$ & $\begin{array}{l}\text { The Spread of True And False News } \\
\text { Online }\end{array}$ & Science & 556 & 2018 \\
\hline Baym (2005) & $\begin{array}{l}\text { The Daily Show: Discursive } \\
\text { Integration And The Reinvention of } \\
\text { Political Journalism }\end{array}$ & Political Communication & 227 & 2005 \\
\hline $\begin{array}{l}\text { Tandoc Jr et al. } \\
\text { (2018) }\end{array}$ & $\begin{array}{l}\text { Defining "Fake News" A Typology } \\
\text { Of Scholarly Definitions }\end{array}$ & Digital Journalism & 195 & 2018 \\
\hline $\begin{array}{l}\text { Allcott and } \\
\text { Gentzkow (2017) }\end{array}$ & $\begin{array}{l}\text { Social Media and Fake News In The } \\
2016 \text { Election }\end{array}$ & $\begin{array}{l}\text { Journal of Economic } \\
\text { Perspectives }\end{array}$ & 191 & 2017 \\
\hline $\begin{array}{l}\text { Lewandowsky, } \\
\text { Ecker, and Cook } \\
\text { (2017) }\end{array}$ & $\begin{array}{l}\text { Beyond Misinformation: } \\
\text { Understanding and Coping With The } \\
\text { "Post-Truth" Era }\end{array}$ & $\begin{array}{l}\text { Journal of Applied Research } \\
\text { in Memory and Cognition }\end{array}$ & 154 & 2017 \\
\hline $\begin{array}{l}\text { Grinberg, Joseph, } \\
\text { Friedland, Swire- } \\
\text { Thompson, and } \\
\text { Lazer (2019) }\end{array}$ & $\begin{array}{l}\text { Fake News in Twitter During The } \\
2016 \text { US Presidential Election }\end{array}$ & Science & 69 & 2019 \\
\hline $\begin{array}{l}\text { Bakir and McStay } \\
\text { (2018) }\end{array}$ & $\begin{array}{l}\text { Fake News and the Economy Of } \\
\text { Emotions: Problems, Causes, } \\
\text { Solutions }\end{array}$ & Digital Journalism & 68 & 2018 \\
\hline $\begin{array}{l}\text { Bennett and } \\
\text { Livingston (2018) }\end{array}$ & $\begin{array}{l}\text { The Disinformation Order: } \\
\text { Disruptive Communication and The } \\
\text { Decline of Democratic Institutions }\end{array}$ & $\begin{array}{l}\text { European Journal of } \\
\text { Communication }\end{array}$ & 68 & 2018 \\
\hline $\begin{array}{l}\text { Vargo, Guo, and } \\
\text { Amazeen (2018) }\end{array}$ & $\begin{array}{l}\text { The Agenda-Setting Power of Fake } \\
\text { News: A Big Data Analysis of The } \\
\text { Online Media Landscape from } 2014 \\
\text { to } 2016\end{array}$ & New Media \& Society & 68 & 2018 \\
\hline $\begin{array}{l}\text { Guess, Nagler, and } \\
\text { Tucker (2019) }\end{array}$ & $\begin{array}{l}\text { Less Than You Think: Prevalence } \\
\text { and Predictors of Fake News } \\
\text { Dissemination on Facebook }\end{array}$ & Science Advances & 63 & 2019 \\
\hline $\begin{array}{l}\text { Pennycook and } \\
\text { Rand (2019) }\end{array}$ & $\begin{array}{l}\text { Lazy, Not Biased: Susceptibility to } \\
\text { Partisan Fake News is Better } \\
\text { Explained By Lack of Reasoning } \\
\text { than by Motivated Reasoning }\end{array}$ & Cognition & 61 & 2019 \\
\hline $\begin{array}{l}\text { Khaldarova and } \\
\text { Pantti (2016) }\end{array}$ & $\begin{array}{l}\text { Fake News: The Narrative Battle } \\
\text { over The Ukrainian Conflict }\end{array}$ & Journalism Practice & 59 & 2016 \\
\hline $\begin{array}{l}\text { Mihailidis and } \\
\text { Viotty (2017) }\end{array}$ & $\begin{array}{l}\text { Spreadable Spectacle in Digital } \\
\text { Culture: Civic Expression, Fake } \\
\text { News, and the Role of Media } \\
\text { Literacies in "Post-Fact" Society }\end{array}$ & $\begin{array}{l}\text { American Behavioral } \\
\text { Scientist }\end{array}$ & 59 & 2017 \\
\hline
\end{tabular}

Note. Citation count was updated in July 2020. 
Table 12 Keywords in Fake News Research

\begin{tabular}{lclc}
\hline Keywords & Articles & Keywords & Articles \\
\hline fake news & 163 & machine learning & 7 \\
social media & 67 & populism & 7 \\
misinformation & 55 & politics & 7 \\
disinformation & 23 & propaganda & 7 \\
post-truth & 19 & elections & 7 \\
twitter & 16 & science & 6 \\
journalism & 16 & trump & 6 \\
media & 15 & news & 6 \\
Facebook & 14 & false news & 6 \\
media literacy & 11 & digital literacy & 6 \\
fact-checking & 11 & alternative facts & 6 \\
trust & 9 & text mining & 5 \\
social networks & 9 & verification & 5 \\
political communication & 8 & polarization & 5 \\
credibility & 8 & narrative & 5 \\
\hline
\end{tabular}

Note. Only keywords that appeared in 5 and more articles were listed.

Table 13 Keywords in Fake News Research by Categories

\begin{tabular}{|c|c|}
\hline Category & Keywords \\
\hline $\begin{array}{l}\text { Fake news and relative } \\
\text { concepts }\end{array}$ & $\begin{array}{l}\text { fake news, misinformation, disinformation, } \\
\text { propaganda, post-truth, false news, alternative facts }\end{array}$ \\
\hline Social media & social media, twitter, Facebook, social networks \\
\hline Social issue & $\begin{array}{l}\text { politics, elections, journalism, media, news, political } \\
\text { communication, polarization, credibility, narrative }\end{array}$ \\
\hline $\begin{array}{l}\text { Fact-checking using Artificial } \\
\text { Intelligence analysis }\end{array}$ & $\begin{array}{l}\text { Machine Learning, fact-checking, text mining, } \\
\text { verification }\end{array}$ \\
\hline Others & $\begin{array}{l}\text { populism, science, trump, media literacy, digital } \\
\text { literacy, trust }\end{array}$ \\
\hline
\end{tabular}

Note. Only keywords that appeared in 5 and more articles were listed.

The content of an abstract can reflect the main focus of the paper. To summarize the main contents of fake news research articles, the current study analyses the content of abstracts. The current study summaries the key terms that frequently appear in abstracts.

A key term can be a single word or a phrase. In the field of text mining, scholars usually use $\mathrm{N}$-gram e when a pre-defined dictionary for a new phrase is not available. $\mathrm{N}$-gram refers to a contiguous sequence of $\mathrm{n}$ terms ( $\mathrm{n}$ can be a number from 1 to any 
number). A single word equals unigram, while $\mathrm{N}$ denotes 1 . A two-word phrase represents 2-gram. The current study used 2-gram and 3-gram to find the frequently used phrases in the abstracts of fake news research articles. The current study did not find any meaningful 4-gram or above phases that had been used for more than ten times. Thus, the paper does not report the 4-gram results. Table 14, Table 15, and Table 16 show the unigram, 2-gram, and 3-gram results.

Table 14 Frequently Used Terms in Abstracts (Uni-Gram)

\begin{tabular}{cccccc}
\hline Term & Frequency & Term & Frequency & Term & Frequency \\
\hline news & 1014 & mainstream & 39 & medical & 23 \\
fake & 618 & truth & 38 & images & 23 \\
media & 543 & Trump & 36 & human & 22 \\
social & 412 & presidential & 35 & citizens & 22 \\
information & 395 & accuracy & 35 & partisan & 22 \\
political & 272 & bots & 32 & journalistic & 21 \\
misinformation & 152 & government & 31 & misleading & 20 \\
public & 147 & journalists & 31 & President & 20 \\
online & 134 & algorithms & 31 & narrative & 20 \\
false & 124 & democracy & 30 & Donald & 19 \\
digital & 91 & websites & 29 & cancer & 17 \\
sources & 88 & verification & 29 & professional & 17 \\
spread & 84 & rumors & 29 & consequences & 17 \\
disinformation & 70 & perceptions & 29 & European & 17 \\
trust & 65 & propaganda & 29 & U.S & 17 \\
election & 62 & narratives & 29 & platform & 17 \\
journalism & 58 & fact-checking & 29 & population & 17 \\
communication & 52 & practices & 29 & accurate & 17 \\
Facebook & 50 & politics & 28 & voters & 17 \\
network & 47 & education & 28 & advertising & 16 \\
negative & 46 & democratic & 27 & identification & 16 \\
post-truth & 45 & Internet & 26 & evaluation & 16 \\
tweets & 43 & cognitive & 23 & propagation & 16 \\
policy & 41 & diffusion & 23 & manipulation & 16 \\
credibility & 39 & satire & 23 & deception & 15 \\
\hline
\end{tabular}

Note. Terms that appear in most academic article, such as prepositions, are not included 
Table 15 Frequently Used Two-word Phases in Abstracts (2-Gram)

\begin{tabular}{lc}
\hline Terms (two-word phase) & Frequency \\
\hline fake news & 563 \\
social media & 265 \\
false news & 47 \\
presidential election & 27 \\
climate change & 20 \\
social bots & 17 \\
mainstream media & 17 \\
public opinion & 13 \\
social network & 11 \\
media environment & 10 \\
\hline
\end{tabular}

Note. This table only includes meaningful phrases of 2-gram results. The normal phrase that appeared in most academic papers or phrases that without meaningful meaning are not included.

Table 15 Frequently Used Three-Word Phases in Abstracts (3- Freque Gram) Terms (three-word phase) ncy the United States 23

$\begin{array}{ll}\text { social media platforms } & 16\end{array}$

$\begin{array}{ll}\text { fake news stories } & 15\end{array}$

$\begin{array}{ll}\text { US presidential election } & 11\end{array}$

Note. This table only includes meaningful phrases of 3-gram results. The normal phrase that appears in most academic papers or phrases that without meaningful meaning are not included.

Table 14 reveals that the terms political (272 times), policy (41 times), democratic (30 times), politics (28 times) was frequently mentioned in abstracts, showing that fake news was related to politics. Besides, the term bots had 32 counts, showing that researchers were concerned about the existence of bots. Besides, accuracy and algorithm were also frequently used, meaning that some research focuses on the detection of fake news detection through fact-checking.

Table 15 reveals that the term social bots were frequently mentioned (17 times), suggesting that social bots were an important issue in fake news research. Besides, fake news, social media, false news, presidential election, climate change, mainstream media, public opinion, social network, and media environment are terms that are frequently discussed. Among these terms, climate change does not directly link to fake news. Nevertheless, some research focused on fake news regarding climate change. 
Showed in Table 16, the 3-gram results show that the United States, social media platforms, fake news stories, and US presidential election were frequently used, suggesting that the United States presidential election was frequently mentioned in fake news research.

Based on the review of keywords and abstracts, we concluded that the theories or models were not frequently used in fake news research. Thus, the study cannot summarize the theories or models used in previous fake news research. The result may be attributed to the fact that most fake news research still positions themselves in introducing the existence of fake news. It is suggested that researchers may try to use theory to further examine the phenomenon of fake news.

\section{DISCUSSION}

Fake news is an emerging issue in cyberspace that attracts a lot of attention from academic communities, journalism, politicians, and even the general public. There are some terms with similar meaning to fake news, such as fake news, news satire, yellow journalism, junk news, pseudo-news, hoax news, propaganda news, advertorial, fake information, false information, misinformation, disinformation, rumor, malinformation, post-truth, and alternative fact. The current study explores the similarity and differences between each of these terms. It is found that although these terms are related to fake news, the core concepts are different between fake news and these terms. The main focus of fake news is the incorrect information contained in the news reports. Fake news is naturally different from news satire, yellow journalism, junk news, pseudo-news, hoax news, propaganda news, advertorial. Besides, fake news discusses incorrect messages spread by the news. Misinformation is mainly about incorrect information, whether the information is spread by news reports or through other channels. Disinformation is also related to fake news. Nevertheless, disinformation discusses if incorrect messages are deliberately created to harm others. Fake information, false information, rumor, mal-information, post-truth, and alternative facts are also related to incorrect messages, whether the messages are delivered by news media or not.

Based on the literature search, the current study found that although all abovementioned terms were related to fake news, only fake news, false news, false information, misinformation, and disinformation were frequently used in academic articles. The present study also found that not all research on misinformation had something to do with fake news research. Some misinformation research studies just discussed misinformation in their research fields.

Before 2016, fake news research was not an eye-catching field. However, the number of published academic papers has dramatically increased since 2017. The 
current study investigates the 387 papers published before 2019 . We also found at least 169 papers were published in the first seven months of 2020. Obviously, the count of published fake news articles in 2020 will keep growing.

The current study found that no dominant journal had published most fake news articles. The journal ranked the top one in number only published 12 articles. Besides, not all journals that published fake news articles were in the field of mass communication. Some journals discussed behavioral issues (such as American Behavioral Scientist) and education (such as Culture and Education). Some others are interdisciplinary journals, such as Social Media and Society, New Media \& Society, Computers In Human Behavior, Online Information Review, and PLOS One.

Besides, the study found that scholars in the United States published most fake news articles compared with scholars in other countries. Scholars in the United States also contributed most fake news articles and were most interested in fake news research.

The current study also found that although fake news is a new issue, some papers had received a lot of citations. These mostly cited articles may be summarized into a good reading list for newcomers of fake news research. Besides, the current study used keywords and abstract analysis to summarize the main content of fake news research, which can reflect the main focus of previous literature. These terms can be collected to help newcomers quickly understand the focus and find promising topics for themselves in this field of research.

Prevent or minimize fake news circulation is important since people prefer to have cyberspace free from fake information. Nevertheless, conspirators with ulterior motives may purposely create, deliver, and distribute fake news. There are a lot of work to deal with and plenty of research issues to be studied.

For example, audiences' attitudes towards fake news, factors influencing fake news sharing, and factors that influence fake news persuasion are also important research topics. Besides, journalism research may be interesting in the source and motivation of fake news generation and distribution. Fact-checking is also an important research issue against anti-fake news. In the past decades, recommendation engines have gained considerable popularity in e-commerce and related fields (Addagarla \& Amalanathan, 2019). These recommendation systems group users based on their shared interests and then promote the same type of content to all users within each group. When the recommendation system obtains information about the truthiness of news, it can help to prevent fake news distribution. 


\section{REFERENCES}

Addagarla, S. K., \& Amalanathan, A. (2019). A survey on comprehensive trends in recommendation systems \& applications. International Journal of Electronic Commerce Studies, 10(1), 65-88. https://doi.org/10.7903/ijecs.1705

Allcott, H., \& Gentzkow, M. (2017). Social media and fake news in the 2016 election. Journal of Economic Perspectives, 31(2), 211-236.

https://doi.org/10.3386/w23089

Bakir, V., \& McStay, A. (2018). Fake news and the economy of emotions: Problems, causes, solutions. Digital Journalism, 6(2), 154-175.

https://doi.org/10.1080/21670811.2017.1345645

Baym, G. (2005). The daily show: Discursive integration and the reinvention of political journalism. Political Communication, 22(3), 259-276.

https://doi.org/10.1080/10584600591006492

Bennett, W. L., \& Livingston, S. (2018). The disinformation order: Disruptive communication and the decline of democratic institutions. European Journal of Communication, 33(2), 122-139. https://doi.org/10.1177/0267323118760317

Chiang, I. P., Wu, Y. J., \& Yang, J.-Y. (2019). Exploring smartphone users' social information behavior. Contemporary Management Research, 15(1), 53-67. https://doi.org/10.7903/cmr.18461

Grinberg, N., Joseph, K., Friedland, L., Swire-Thompson, B., \& Lazer, D. (2019). Fake news on Twitter during the 2016 US presidential election. Science, 363(6425), 374-378. https://doi.org/10.1126/science.aau2706

Guess, A., Nagler, J., \& Tucker, J. (2019). Less than you think: Prevalence and predictors of fake news dissemination on Facebook. Science Advances, 5(1), eaau4586. https://doi.org/10.1126/sciadv.aau4586

Khaldarova, I., \& Pantti, M. (2016). Fake news: The narrative battle over the Ukrainian conflict. Journalism Practice, 10(7), 891-901.

https://doi.org/10.1080/17512786.2016.1163237

Lewandowsky, S., Ecker, U. K., \& Cook, J. (2017). Beyond misinformation: Understanding and coping with the "post-truth" era. Journal of Applied Research in Memory and Cognition, 6(4), 353-369.

https://doi.org/10.1016/i.jarmac.2017.07.008

Mihailidis, P., \& Viotty, S. (2017). Spreadable spectacle in digital culture: Civic expression, fake news, and the role of media literacies in "post-fact" society. American Behavioral Scientist, 61(4), 441-454. https://doi.org/10.1177/0002764217701217

Molina, M. D., Sundar, S. S., Le, T., \& Lee, D. (2019). "Fake news" is not simply false information: a concept explication and taxonomy of online content. 
American Behavioral Scientist, 000276421987822.

https://doi.org/10.1177/0002764219878224

Noh, H., Jo, Y., \& Lee, S. (2015). Keyword selection and processing strategy for applying text mining to patent analysis. Expert Systems with Applications, 42(9), 4348-4360. https://doi.org/10.1016/j.eswa.2015.01.050

Pennycook, G., \& Rand, D. G. (2019). Lazy, not biased: Susceptibility to partisan fake news is better explained by lack of reasoning than by motivated reasoning. Cognition, 188, 39-50. https://doi.org/10.1016/j.cognition.2018.06.011

Persily, N. (2017). The 2016 US Election: Can democracy survive the internet? Journal of Democracy, 28(2), 63-76. https://doi.org/10.1353/jod.2017.0025

Tandoc Jr, E. C., Lim, Z. W., \& Ling, R. (2018). Defining “fake news" A typology of scholarly definitions. Digital Journalism, 6(2), 137-153.

https://doi.org/10.1080/21670811.2017.1360143

Vargo, C. J., Guo, L., \& Amazeen, M. A. (2018). The agenda-setting power of fake news: A big data analysis of the online media landscape from 2014 to 2016 . New Media \& Society, 20(5), 2028-2049. https://doi.org/10.1177/1461444817712086

Vosoughi, S., Roy, D., \& Aral, S. (2018). The spread of true and false news online. Science, 359(6380), 1146-1151. https://doi.org/10.1126/science.aap9559

Westlund, O. (2013). Mobile news: A review and model of journalism in an age of mobile media. Digital Journalism, 1(1), 6-26.

https://doi.org/10.1080/21670811.2012.740273

Yang, Y.-J., \& Hwang, J.-C. (2020). Recent development trend of blockchain technologies: A patent analysis. International Journal of Electronic Commerce Studies, 11(1), 1-12. https://doi.org/10.7903/ijecs.1931

Prof. Chih-Chien Wang is currently a distinguished professor at the Graduate Institute of Information Management, National Taipei University, Taiwan. He has authored and coauthored several textbooks and more than one hundred journal and conference papers. His research interests are in the areas of fake news, anti-spammer, electronic commerce, internet marketing, cyber society, and online behavior. 